\title{
Optimum Ridge Regression Parameter Using R-Squared of Prediction as a Criterion for Regression Analysis
}

\author{
Akbar Irandoukht ${ }^{*}$ \\ Catalysis Division, Research Institute of Petroleum Industry, Tehran, 1485733111, Iran
}

\section{ARTICLE INFO}

Article History

Received 19 Aug 2018

Accepted 09 Apr 2019

\section{Keywords}

Ridge parameter

PRESS

Maximization of $\mathrm{R}^{2}$-prediction

Model prediction power

\begin{abstract}
The presence of the multicollinearity problem in the predictor data causes the variance of the ordinary linear regression coefficients to be increased so that the prediction power of the model not to be satisfied and sometimes unacceptable results be predicted. The ridge regression has been proposed as an efficient method to combat multicollinearity problem long ago. In application of ridge regression the researcher uses the ridge trace and selects a value of ridge parameter in such a manner that he thinks the regression coefficients have stabilized; this leads the ridge regression to be subjective technique. The purpose of this paper is the conversion of the ridge regression method from a qualitative method to a quantitative one meanwhile to present a method to find the optimum ridge regression parameter which maximizes the $R$-squared of prediction. We examined four well-known case studies on this regard. Significant improvements at all of the cases demonstrated the validity of our proposed method.
\end{abstract}

(c) 2021 The Authors. Published by Atlantis Press B.V. This is an open access article distributed under the CC BY-NC 4.0 license (http://creativecommons.org/licenses/by-nc/4.0/).

\section{INTRODUCTION}

In many scientific and engineering disciplines, the researchers face to study the effect of some input or predictor variables on an output or response variable. After performing experiments, which are usually done either in classical one-factor-at-time method or using experimental design patterns, there is a need to relate the input variables to output variable via a characterizing mathematical relationship. Hence, if there is a theoretical relationship between $\mathbf{Y}$ and $\mathbf{X}$, then the form of the relating function will be specified. If the theoretical functionality has not been developed, then the researcher may use empirical linear models using some parameter $\beta$. The values of these parameters can be estimated by using linear regression technique $[7,8,18,30,36,37,39,40,41,48]$.

Sometimes the number of predictor variables is large or predictors are not really independent and there may be some correlations between input variables. In these cases, the relationship $\mathrm{Xi} . \mathrm{Xj}=0$ dose not satisfy. The presence of correlation between predictor variables produces the multicollinearity problem. The effects of collinearity have been discussed by above mentioned researchers and also by Gunst [19], Jensen and Ramirez [28].

The significant number of methods has been proposed to overcome multicollinearity problem (e.g., see [3,14,15,17,41]).

One of the efficient methods to combat the multicollinearity problems is ridge regression developed by Hoerl [23], Hoerl and Kennard $[24,25]$ for the first time. Many researchers used it in practice and found it useful on this regard for example see Marquardt [33], Hemmerle [20], Marquardt and Snee [34], Khuri and Myers [30], Dorugade [5], Fitrianto and Yik [13], Yahya and Olaifa [48].

Hoerl and Kennard [26] themselves published the first review paper on ridge regression and then other reviews appeared in the literature, among them, the works of Singh [43], Dube and Isha [9], Duzan and Shariff [10], Goktas and Sevinc [16] can be mentioned.

Some of the researchers tried to show the application and usefulness of ridge regression using simulation studies $[6,11,27,32,42]$.

On the other hand some researchers criticized the ridge regression method from different points of view for example see Smith and Campbel [44], and also the comments of Thisted et al. were appeared in the same issue of Journal of American Statistical Association (1980); Draper and Smith [7], Singh [43], Chatterjee and Hadi [3].

One of the main weaknesses of the ridge regression is that the ridge regression parameter can be selected by examining the ridge trace (Marquardt and Snee [34] points out that for using ridge regression 25 values of $\mathrm{k}$ in the interval of [0 1] need to be examined). 
A large number of methods have been proposed to calculate the ridge parameter (see $[9,10,16,33,43]$ compare 39 methods of estimating ridge parameters). By considering these at all; one may conclude that the ridge regression is a subjective method. The first objective of this paper is to convert the ridge regression method from a qualitative method to a quantitative one meanwhile the second objective is to present a method to find the optimum ridge regression parameter which maximizes the prediction power of a given model using ridge regression with optimum ridge parameter.

\section{METHOD}

As is obvious one of the main reasons for making a good model from data is not merely the prediction of the given responses from predictor variables, and we are also interested in predicting the values of response at other conditions where there are not any data. Hence the prediction power of the model is so crucial. The R-squared of prediction and also prediction residual sum of squares can be considered as good measures on this regard $[1,2,4,12,17,22]$. Let us below have a look on the related formula:

$$
\mathrm{R}^{2} \text {-prediction }=1-\mathrm{PRESS} / \mathrm{SST}
$$

where PRESS is the total prediction residual sum of squares and SST is the total sum of squares.

$$
\begin{gathered}
\text { PRESS }=\sum \mathrm{e}^{2}(\mathrm{i})=\sum(\text { yi-y }(\mathrm{i})) 2 \\
\text { SST }=\sum(\text { yi-ymean }) 2 \\
\text { Ypred }=\text { HY }
\end{gathered}
$$

This can be obtained using leave-one-out cross-validation technique. The PRESS residual for ith data is

$$
\mathrm{e}(\mathrm{i})=\mathrm{ei} /(1-\mathrm{hii})
$$

The values of hii are the diagonal elements of the hat matrix associated with ridge regression parameter calculated below.

$$
\begin{aligned}
& \mathbf{H}=\mathbf{X}\left(\mathbf{X}^{\prime} \mathbf{X}+\mathrm{k} \mathbf{I}\right)^{-1} \mathbf{X}^{\prime} \\
& \beta^{*}=\left(\mathbf{X}^{\prime} \mathbf{X}+\mathrm{k} \mathbf{I}\right)^{-1} \mathbf{X}^{\prime} \mathbf{Y}
\end{aligned}
$$

In this equation $\mathbf{X}$ is predictors matrix with 1's in the first column, $\mathbf{X}$ ' is the transpose of the predictors matrix, $\mathbf{I}$ is the identity matrix, $k$ is the ridge regression parameter, and $\beta^{\star}$ is the coefficients of the given model using ridge regression technique. If $\mathrm{k}$ equals zero the ridge regression converts to the ordinary least square regression.

We propose that the value of ridge regression parameter which maximizes the $R^{2}$-prediction is said to be the optimum ridge parameter, the numerical value of the ridge parameter $k$, can be obtained by using an optimizer via trial and error operation.

\section{RESULTS AND DISCUSSION}

In order to illustrate the validity of our method to determine the optimum ridge regression parameter we will deal with four examples namely acetylene conversion, French import economy, heat evolved on cement hardening, and propellant mechanical property.

\subsection{Acetylene Conversion}

Original data of converting normal heptane to acetylene were collected by Kunugi et al. [31]. Himmelblau [21], presented information of this conversion data which were used by other researchers as a classical example when they dealt with ridge regression to overcome the multicollinearity problem (see $[34,35,37,45,46])$.

Here we will consider four different models to show the application of our proposed method, namely main effect model, interaction model, reduced model, and full quadratic model as below:

$$
\begin{gathered}
\text { gy-main effect }=\mathrm{a} 0+\mathrm{a} 1 \mathrm{X} 1^{*}+\mathrm{a} 2 \mathrm{X} 2^{*}+\mathrm{a} 3 \mathrm{X} 3^{*} \\
\mathrm{y} \text {-interaction }=\mathrm{b} 0+\mathrm{b} 1 \mathrm{X} 1^{*}+\mathrm{b} 2 \mathrm{X} 2^{*}+\mathrm{b} 3 \mathrm{X} 3^{*}+\mathrm{b} 4 \mathrm{X} 1^{*} \mathrm{X} 2^{*}+\mathrm{b} 5 \mathrm{X} 1^{*} \mathrm{X} 3^{*}+\mathrm{b} 6 \mathrm{X} 2^{*} \mathrm{X} 3^{*}
\end{gathered}
$$




$$
\begin{aligned}
\text { y-reduced }= & c 0+c 1 X 1^{*}+c 2 X 2^{*}+c 3 X 3^{*}+c 4 X 1^{*} X 2^{*}+c 5 X 1^{*} X 1^{*} \\
y \text {-quadratic }= & d 0+d 1 X 1^{*}+d 2 X 2^{*}+d 3 X 3^{*}+d 4 X 1^{*} X 2^{*}+d 5 X 1^{*} X 3^{*} \\
& +d 6 X 2^{*} X 3^{*}+d 7 X 1^{*} X 1^{*}+d 8 X 2^{*} X 2^{*}+d 9 X 3^{*} X 3^{*}
\end{aligned}
$$

Here, as mentioned by Marquardt and Snee [34]; X1*, X2* and X3* are the centered and scaled forms of the original variables as defined below:

$$
\begin{gathered}
\mathrm{X} 1^{*}=(\mathrm{T}-1212.5) / 80.623 \\
\mathrm{X} 2^{*}=(\mathrm{H} 2 / \text { Heptane ratio-12.44 }) / 5.662 \\
\mathrm{X} 3^{*}=(\text { contact time }-0.0403) / 0.03164
\end{gathered}
$$

The coefficients of ai's, bi's, ci's, and di's could easily be calculated using ordinary least squares technique.

Table 1 presents the $\mathbf{X}$ matrix for main effect model, whereas in Table 2 the statistics of PRESS, $R^{2}$, SST, and also $R^{2}$-prediction at different values of ridge parameter for main effect model are tabulated.

Table $\mathbf{1}$ Predictors matrix, $\mathbf{X}$ for main effect model of acetylene data.

\begin{tabular}{cccc}
\hline & $\mathbf{X 1}^{*}$ & $\mathbf{X 2}^{*}$ & $\mathbf{X 3}^{*}$ \\
\hline 1 & 1.085304 & -0.87314 & -0.89487 \\
1 & 1.085304 & -0.60822 & -0.89487 \\
1 & 1.085304 & -0.25499 & -0.91068 \\
1 & 1.085304 & 0.18655 & -0.86327 \\
1 & 1.085304 & 0.804702 & -0.84746 \\
1 & 1.085304 & 1.864392 & -0.89487 \\
1 & -0.15504 & -1.26169 & -0.00988 \\
1 & -0.15504 & -0.87314 & -0.07309 \\
1 & -0.15504 & -0.25499 & -0.26273 \\
1 & -0.15504 & 0.18655 & -0.45238 \\
1 & -0.15504 & 0.804702 & -0.19952 \\
1 & -0.15504 & 1.864392 & 0.02173 \\
1 & -1.39539 & -1.26169 & 1.380833 \\
1 & -1.39539 & -0.87314 & 1.823331 \\
1 & -1.39539 & -0.25499 & 1.633689 \\
1 & -1.39539 & 0.804702 & 1.444047 \\
\hline
\end{tabular}

Table 2 Statistics for main effect model at different values of $k$ parameter.

\begin{tabular}{lcccccccc}
\hline Ridge, $\boldsymbol{k}$ & $\mathbf{0}$ & $\mathbf{0 . 0 4}$ & $\mathbf{0 . 0 1 6}$ & $\mathbf{0 . 0 6 4}$ & $\mathbf{0 . 1 2 8}$ & $\mathbf{0 . 1 7 8 7 4 3}$ & $\mathbf{0 . 2 5 6}$ & $\mathbf{0 . 5 1 2}$ \\
\hline PRESS & 336.2955 & 332.3246 & 334.5347209 & 330.5745 & 327.785 & $\mathbf{3 2 7 . 1 7 2 7}$ & 328.4182 & 346.5632 \\
$R^{2}$ & 0.919815 & 0.919768 & 0.919806742 & 0.919703 & 0.91944 & $\mathbf{0 . 9 1 9 1 7 2}$ & 0.918715 & 0.917167 \\
SST & 2123.709 & 2123.709 & 2123.709375 & 2123.709 & 2123.709 & $\mathbf{2 1 2 3 . 7 0 9}$ & 2123.709 & 2123.709 \\
$R^{2}$-pred & 0.841647 & 0.843517 & 0.842476224 & 0.844341 & 0.845654 & $\mathbf{0 . 8 4 5 9 4 3}$ & 0.845356 & 0.836812 \\
\hline
\end{tabular}

Tables 3 and 4 show those statistics for interaction and reduced models respectively.

Table 3 Statistics for interaction model at different values of $k$ parameter.

\begin{tabular}{lcccccccc}
\hline Ridge, $\boldsymbol{k}$ & $\mathbf{0}$ & $\mathbf{0 . 0 0 4}$ & $\mathbf{0 . 0 1 6}$ & $\mathbf{0 . 0 3 2}$ & $\mathbf{0 . 0 5 4 1 5 5}$ & $\mathbf{0 . 0 6 4}$ & $\mathbf{0 . 1 2 8}$ & $\mathbf{0 . 2 5 6}$ \\
\hline PRESS & 46.3023 & 44.54459 & 41.01827 & 38.77256 & $\mathbf{3 7 . 9 6 5 0 7}$ & 38.07526 & 41.79881 & 55.08884 \\
$R^{2}$ & 0.994565 & 0.994561 & 0.994518 & 0.99441 & $\mathbf{0 . 9 9 4 2 0 7}$ & 0.994104 & 0.993332 & 0.991444 \\
SST & 2123.709 & 2123.709 & 2123.709 & 2123.709 & $\mathbf{2 1 2 3 . 7 0 9}$ & 2123.709 & 2123.709 & 2123.709 \\
$R^{2}$-pred & 0.978197 & 0.979025 & 0.980686 & 0.981743 & $\mathbf{0 . 9 8 2 1 2 3}$ & 0.982071 & 0.980318 & 0.97406 \\
\hline
\end{tabular}


The variations of those statistics for full quadratic model are demonstrated in Figures 1-3.

The data for Figure 4 have been obtained from Myers and Montgomery ([37] Table A.2.4 page 678).

Investigation of the data reveal that there is an optimum value for ridge regression parameter $k$, where PRESS is at minimum and $R^{2}$ prediction at the maximum value. Bold numbers show the optimum ridge parameter and its corresponding statistics in Tables $2-4$.

Comparison of those statistics for full quadratic model at $k=0$, with the corresponding values of ridge parameters proposed by other researchers (Maraquardt and Snee, 1975, and Snee [46], $k=0.01,0.05$; Myers and Montgomery [37], and Montgomery et al. [35], $k=0.008$, 0.032 , and 0.064 ), and also at optimum value of ridge regression parameter are illustrated in Table 5.

Table 4 Statistics for reduced model at different values of $k$ parameter.

\begin{tabular}{|c|c|c|c|c|c|c|c|c|}
\hline Ridge, $k$ & 0 & 0.001 & 0.004 & 0.005 & 0.006667 & 0.01 & 0.015 & 0.02 \\
\hline PRESS & 37.82797 & 37.79893 & 37.74268 & 37.73343 & 37.72765 & 37.74905 & 37.85204 & 38.0249 \\
\hline$R^{2}$ & 0.993708 & 0.993708 & 0.993703 & 0.993701 & 0.993696 & 0.993681 & 0.993652 & 0.993613 \\
\hline SST & 2123.709 & 2123.709 & 2123.709 & 2123.709 & 2123.709 & 2123.709 & 2123.709 & 2123.709 \\
\hline$R^{2}$-pred & 0.982188 & 0.982201 & 0.982228 & 0.982232 & 0.982235 & 0.982225 & 0.982176 & 0.982095 \\
\hline
\end{tabular}

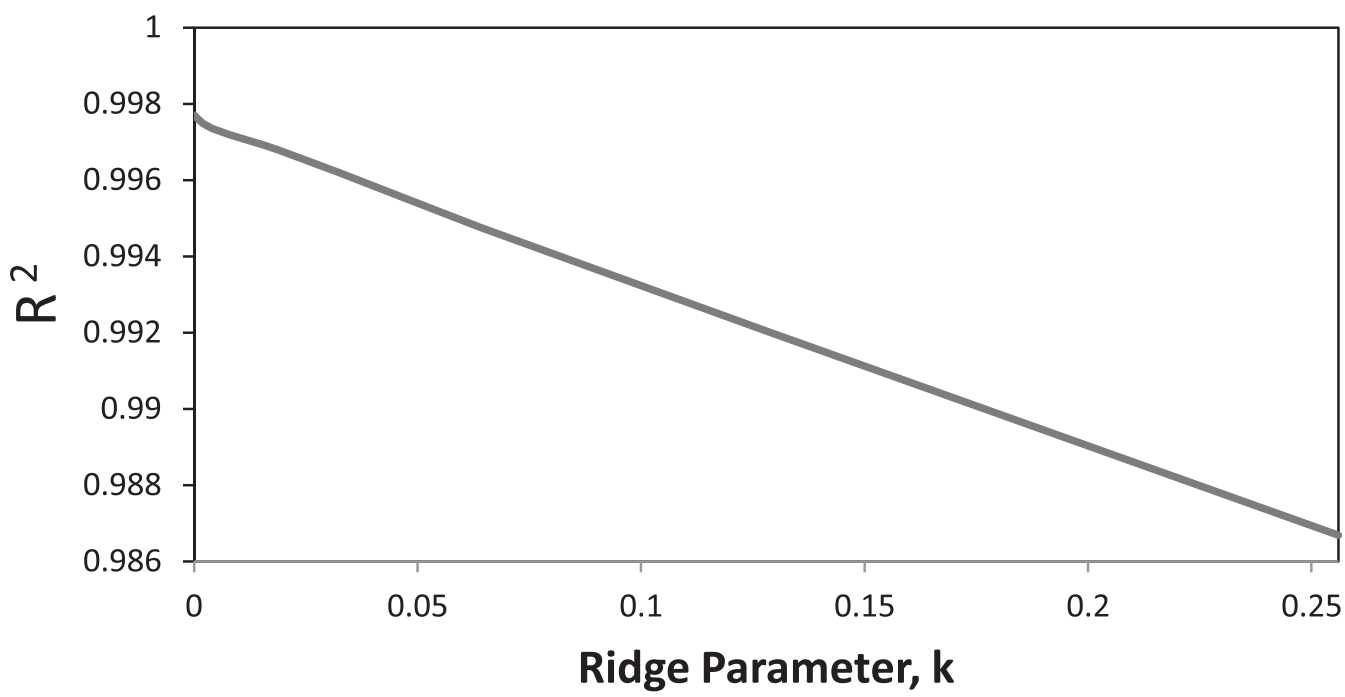

Figure $1 \mid R$-square for full quadratic model.

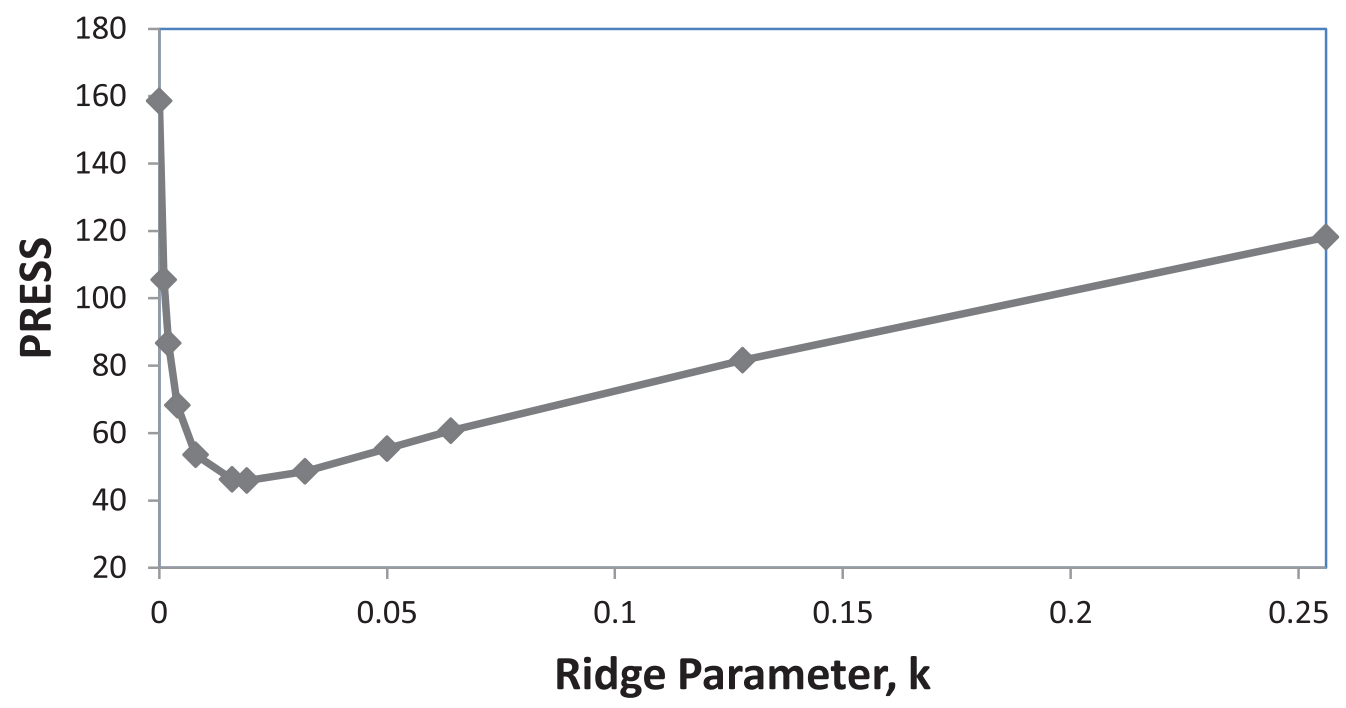

Figure 2 PRESS for full quadratic model. 


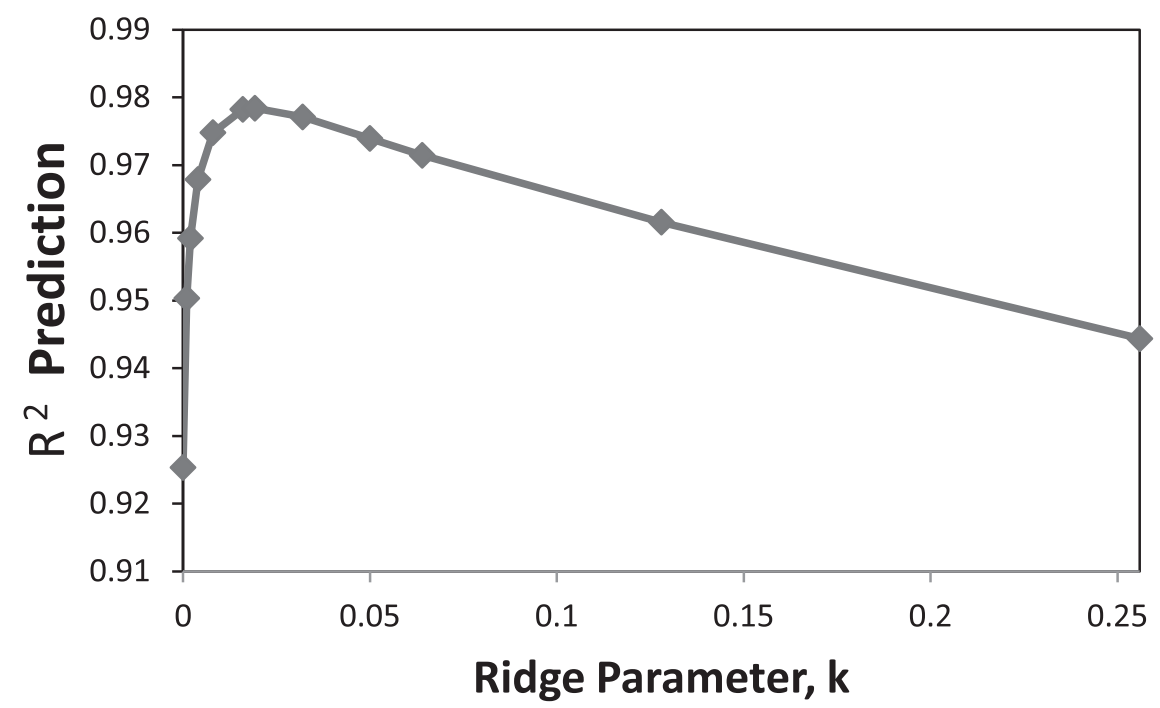

Figure $3 \quad R^{2}$-prediction for full quadratic model.

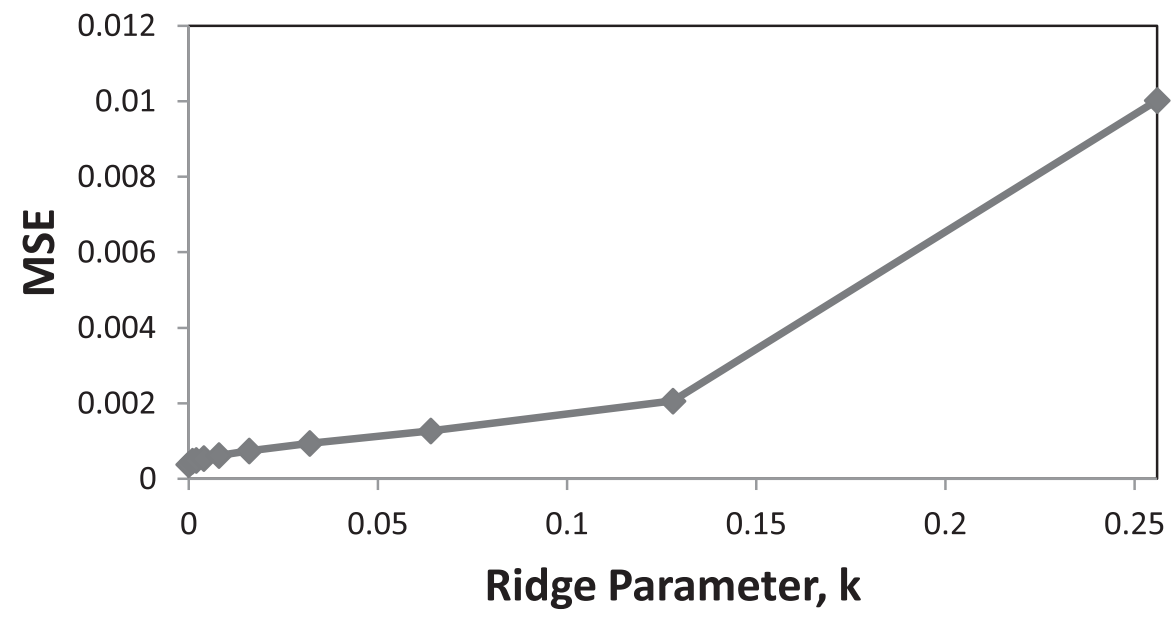

Figure 4 Mean squared of error for full quadratic model.

Table 5 Comparison of statistics at different values of ridge parameter for full quadratic model which have been proposed by other researchers.

\begin{tabular}{lccccccc}
\hline \multicolumn{7}{c}{ OLt-RR } \\
\hline Ridge, $\boldsymbol{k}$ & $\mathbf{0 . 0 0 0 0 0}$ & $\mathbf{0 . 0 0 8 0 0}$ & $\mathbf{0 . 0 1 0 0 0}$ & $\mathbf{0 . 0 1 9 2 3}$ & $\mathbf{0 . 0 3 2 0 0}$ & $\mathbf{0 . 0 5 0 0 0}$ & $\mathbf{0 . 0 6 4 0 0}$ \\
\hline PRESS & 158.56920 & 53.54655 & 50.23883 & $\mathbf{4 5 . 8 9 6 5 8}$ & 48.63185 & 55.36370 & 60.67380 \\
$R^{2}$ & 0.99770 & 0.99719 & 0.99712 & $\mathbf{0 . 9 9 6 7 7}$ & 0.99622 & 0.99540 & 0.99476 \\
SST & 2123.70938 & 2123.70938 & 2123.70938 & $\mathbf{2 1 2 3 . 7 0 9 3 8}$ & 2123.70938 & 2123.70938 & 2123.70938 \\
$R^{2}$-PRED & 0.92533 & 0.97479 & 0.97634 & $\mathbf{0 . 9 7 8 3 9}$ & 0.97710 & 0.97393 & 0.97143 \\
\hline
\end{tabular}

Examination of the data in Table 5 shows that there are two important points. The first one is existing improvements in the values of PRESS and $R^{2}$-prediction at all proposed values of ridge parameters against ordinary least square. The next issue is that the most significant improvement in PRESS and $R^{2}$-prediction appear at the optimum value of the ridge regression parameter where PRESS is at lowest and $R^{2}$-rediction is at highest value. Comparison of the PRESS and $R^{2}$-prediction for different models at their optimum ridge parameter, show that our method can also be used as a criterion for model selection too, on this regard the models using optimum $k$ can be arranged in the following merit order: 


\subsection{French Economy}

The French Import data for the years 1949-1966 were presented and analyzed by Chatterjee and Hadi [3], using principal component as well as ridge regression analysis. The three predictor variables were domestic production, stock formation, and domestic consumption; the response variable is French import; predictor and response variables are all in billions of francs.

They reported three values for ridge regression parameter using Hoerl et al. [27] equation (0.0164); Hoerl and Kennard [25] iterative method (0.0161); and investigating the ridge trace (0.04) where it is stabilized.

Figure 5 shows the variation of PRESS as a function of ridge parameter, whereas Figure 6 demonstrates the variation of $R^{2}$-prediction versus $k$.

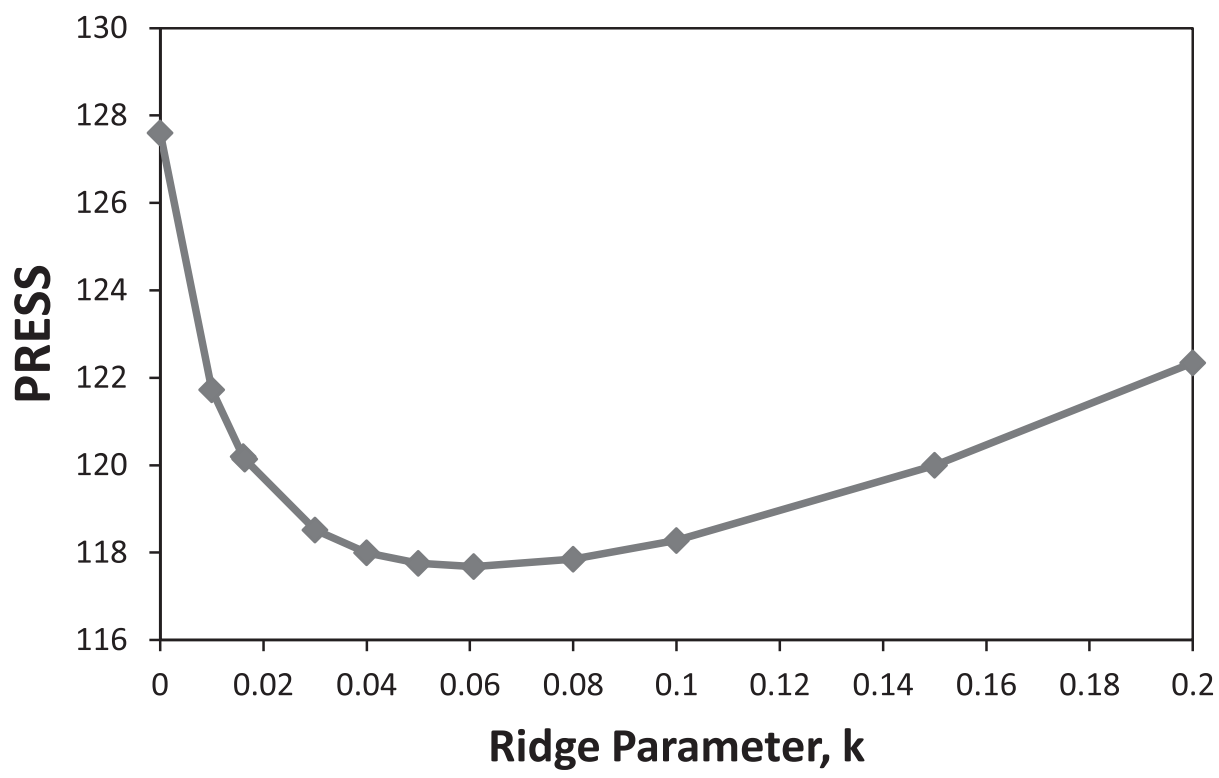

Figure 5 PRESS for French import economy data.

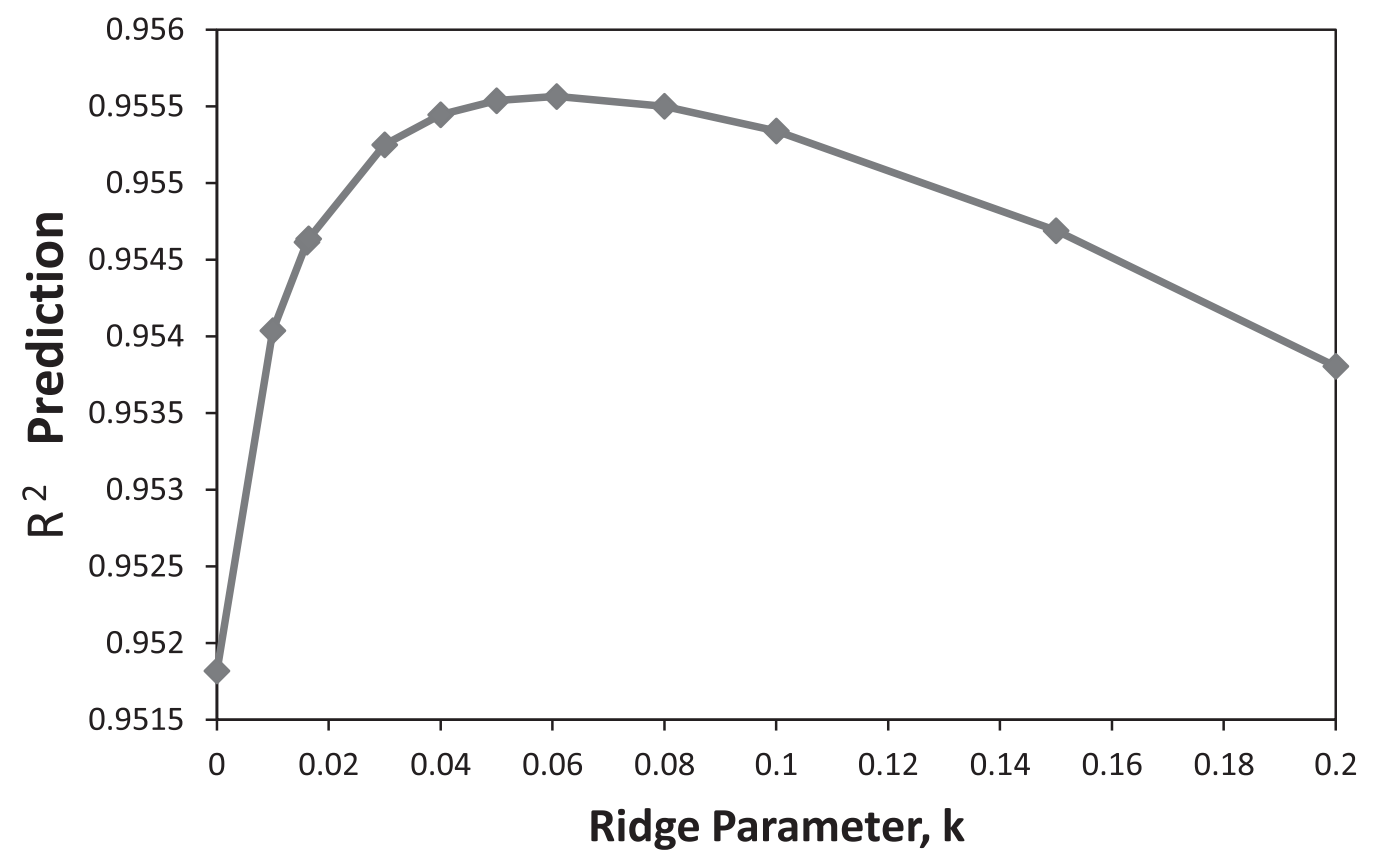

Figure $6 R^{2}$-prediction for French import economy data. 
The optimum value for ridge parameter in this example was calculated as 0.06074 where the crest and hill for PRESS and $R^{2}$-prediction appears as shown in related figures.

\subsection{Hald Data for Portland Cement Composition}

The data set for Hald data can be found in Appendices B and C of Draper and Smith [7], and also in Table 10.10 of Chatterjee and Hadi [3]. The aim of the study was to investigate the amount of heat evolved during the cement hardening as a function of Portland cement constituents. Centered and scaled of the Hald data provides the predictor matrix of $\mathbf{X}$, tabulated in Table 6.

Draper and Smith (1987) reported a value for ridge regression parameter using Hoerl et al. [27] equation (0.0131). In Table 7 we report the statistics of PRESS, $R^{2}$, SST, and also $R^{2}$-prediction at different values of ridge parameter for the main effect model. We observe the crest for PRESS and hill for $R^{2}$-prediction appear at ridge parameter of 0.02991 , which is the optimum value.

Table 6 Predictors matrix, X for main effect model of Hald data.

\begin{tabular}{ccccc}
\hline & $\mathbf{X 1}^{*}$ & $\mathbf{X 2}^{*}$ & $\mathbf{X 3}^{*}$ & $\mathbf{X 4}^{*}$ \\
\hline 1 & -0.07846 & -1.42369 & -0.90072 & 1.79231 \\
1 & -1.09845 & -1.2309 & 0.504404 & 1.31436 \\
1 & 0.601534 & 0.504223 & -0.58847 & -0.59744 \\
1 & 0.601534 & -1.10237 & -0.58847 & 1.015642 \\
1 & -0.07846 & 0.247168 & -0.90072 & 0.179231 \\
1 & 0.601534 & 0.439959 & -0.43235 & -0.47795 \\
1 & -0.75846 & 1.468179 & 0.816654 & -1.43385 \\
1 & -1.09845 & -1.10237 & 1.597278 & 0.836411 \\
1 & -0.92845 & 0.375696 & 0.972779 & -0.47795 \\
1 & 2.301522 & -0.07415 & -1.21297 & -0.23897 \\
1 & -1.09845 & -0.524 & 1.753403 & 0.238975 \\
1 & 0.601534 & 1.14686 & -0.43235 & -1.07539 \\
1 & 0.431535 & 1.275388 & -0.58847 & -1.07539 \\
\hline
\end{tabular}

Table 7 Comparison statistics at different values of ridge parameter for main effect model.

\begin{tabular}{|c|c|c|c|c|c|c|c|c|}
\hline & OLS & & & & Opt-RR & & & \\
\hline Ridge, $k$ & 0 & 0.01 & 0.0131 & 0.02 & 0.02991 & 0.05 & 0.08 & 0.1 \\
\hline PRESS & 110.3466 & 100.6498 & 99.45204 & 97.92197 & 97.29514 & 98.99015 & 105.8798 & 112.6457 \\
\hline$R^{2}$ & 0.982376 & 0.982347 & 0.982336 & 0.982312 & 0.982284 & 0.982243 & 0.982201 & 0.982179 \\
\hline SST & 2715.763 & 2715.763 & 2715.763 & 2715.763 & 2715.763 & 2715.763 & 2715.763 & 2715.763 \\
\hline$R^{2}$-Pred & 0.959368 & 0.962939 & 0.96338 & 0.963943 & 0.964174 & 0.96355 & 0.961013 & 0.958522 \\
\hline
\end{tabular}

\subsection{Propellant Property}

The data set for mechanical property of propellant data were presented by Khuri and Myers [30], and also in Table 5.12 of Khuri and Cornell [29]. The aim of the study was to maximize the certain mechanical modular property of propellant as a function concentration of three substances. Due to practical problems, instead of central composite design they used deformed Central Composite Design (CCD) design for doing experiments which caused multicollinearity problem.

Since they reported the coded data, without centering and scaling, the predictor matrix is tabulated in Table 8 . For this example we report the statistics of Total prediction residual sum of squares (PRESS), $R^{2}$, SST, and also $R^{2}$-prediction at different values of ridge parameter in Table 9.

Comparing the PRESS and $R^{2}$-prediction values for ordinary least square $(425.92,0.197)$ and at optimal value of $k=0.011055$ (96.02, 0.819$)$, one can conclude that a significant improvement have been achieved using optimal ridge regression parameter.

\section{CONCLUSION}

A large number of methods for estimating the values of the ridge regression parameters have been appeared in the literature and all of them were shown to be better than ordinary least square method based on mean squared criterion. This makes the possibility of being infinite number of solutions for the multicollinearity problem. 
Table 8 Predictors matrix, $\mathbf{X}$ for quadratic model of propellant data.

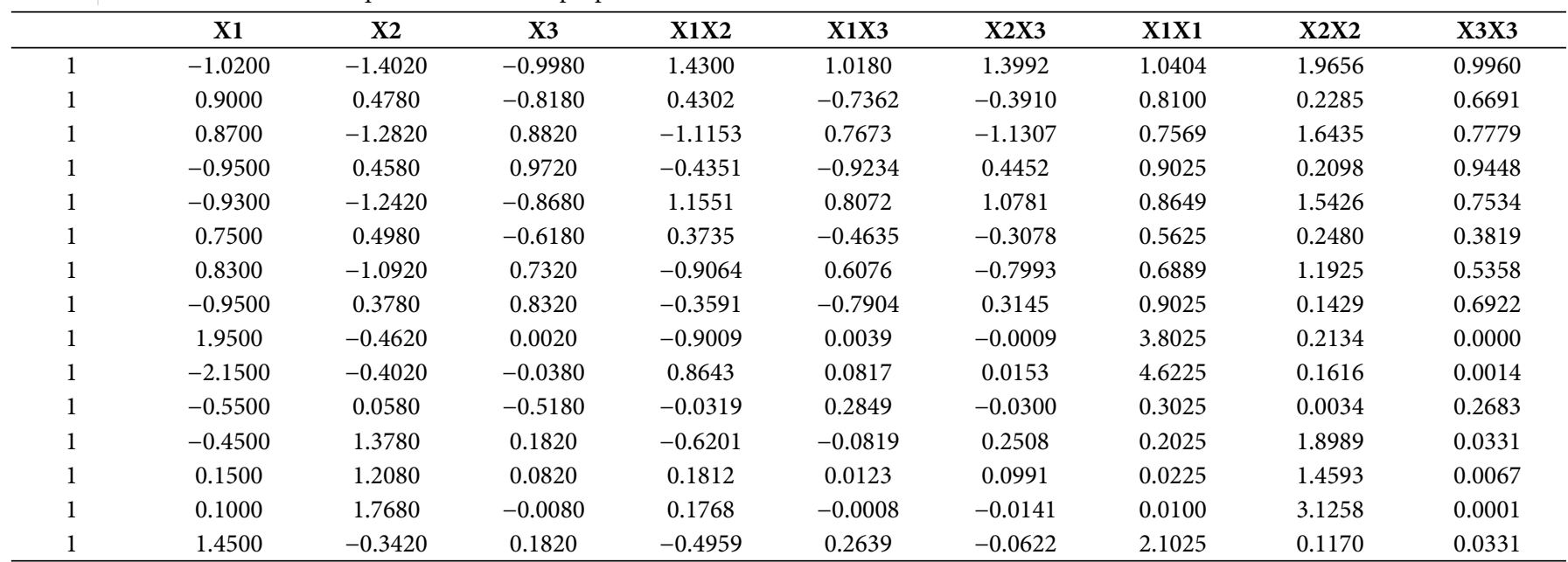

Table 9 Comparison of statistics at different values of ridge parameter for quadratic mode of propellant data.

\begin{tabular}{|c|c|c|c|c|c|c|c|c|}
\hline & OLS & & & Opt-RR & & & & \\
\hline Ridge, $k$ & 0 & 0.01 & 0.05 & 0.11055 & 0.2 & 0.4 & 0.6 & 0.8 \\
\hline PRESS & 425.924458 & 309.6907 & 132.8877 & 96.01921 & 113.2438 & 156.5302 & 181.3001 & 196.5669 \\
\hline$R^{2}$ & 0.97380208 & 0.973542 & 0.970812 & 0.964929 & 0.954975 & 0.934266 & 0.917839 & 0.904814 \\
\hline $\begin{array}{l}\text { Total sum } \\
\text { of squares } \\
\text { (SST) }\end{array}$ & 530.351955 & 530.352 & 530.352 & 530.352 & 530.352 & 530.352 & 530.352 & 530.352 \\
\hline$R^{2}$-Pred & 0.19690226 & 0.416066 & 0.749435 & 0.818952 & 0.786474 & 0.704856 & 0.658151 & 0.629365 \\
\hline
\end{tabular}

Although that is not so bad, the researcher always prefers to find a unique solution for his or her problem at hand. Maximization of $R^{2}$ prediction as a criterion to select the optimum ridge parameter may be considered as an excellent answer on this regard.

As demonstrated in the four case studies, our proposed method lead to the significant improvements in the prediction power of the given models at a unique solution of ridge regression parameter, meanwhile maximization of $R^{2}$-prediction can also be applied in model selection problem among different possible candidates using ridge regression technique.

\section{CONFLICTS OF INTEREST}

The authors declare of no conflicts of interest.

\section{Funding Statement}

The Catalysis Division of Research Institute of Petroleum Industry (Project No. 83990061) supported this work.

\section{ACKNOWLEDGMENTS}

The author would like to thank the Editor-in-Chief, and Associate Editor for their useful comments.

\section{REFERENCES}

1. D.M. Allen, Technometrics. 13 (1971), 469-475.

2. D.M. Allen, Technometrics. 16 (1974), 125-127.

3. S. Chatterjee, A.S. Hadi, Regression Analysis by Example, fifth ed., John Wiley and Sons, InC., Hoboken, New Jersey, UAS, 2012.

4. A. Bartoli, Int. J. Vis. 85 (2009), 133-142.

5. A.V. Dorugade, J. Assoc. Arab Univ. Basic Appl. Sci. 15 (2014), 94-99.

6. A.V. Dorugade, D.N. Kashid, Appl. Math. Sci. 4 (2010), 456-477. 
7. N. Draper, H. Smith, Applied Regression Analysis, second ed., John Wiley and Sons, USA, 1987.

8. N. Draper, R.C. Van Nostrand, Technometrics. 21 (1979), 451-467.

9. M. Dube, Isha, Math. J. Interdiscip. Sci. 3 (2014), 73-83.

10. H. Duzan, N.S.B.M. Shariff, J. Appl. Sci. 15 (2015), 392-404.

11. K. Fathi Vajargah, J. Comput. Sci. Comput. Math. 3 (2013), 25-29.

12. B. McWilliams, G. Montana, J. Comput. Sci. Comput. Math. UK Workshop on Computational Intelligence, IEEE, Colchester, UK, (2010), $25-29$.

13. A. Fitrianto, L.C. Yik, J. Math. Stat. 10 (2014), 25-29.

14. I.E. Frank, J.H. Friedman, Technometrics. 35 (1993), 109-135.

15. C.G. Garcia, J.G. Perez, J.S. Liria, Qual. Quant. 45 (2011), 403-423.

16. A. Goktas, V. Sevinc, Gazi Univ. J. Sci. 29 (2016), 201-211.

17. G.H. Golub, M. Heath, G. Wahba, Technometrics. 21 (1979), 215-223.

18. J.R. Green, D. Margerison, Statistical Treatment of Experimental Data, Elsevier Scientific Publishing Company, Amsterdam, fifth impression, 1988.

19. R.F. Gunst, Commun. Statist. Theor. Meth. 12 (1983), 2217-2260.

20. W.J. Hemmerle, Technometrics. 17 (1975), 309-314.

21. D.M. Himmelblau, Process Analysis by Statistical Methods, John Wiley and Sons Inc., New York, NY, USA, 1970.

22. D.C. Hoaglin, R.E. Welsch, Am Stat. 32 (1978), 17-22.

23. A.E. Hoerl, Chem. Eng. Prog. 58 (1962), 54-59.

24. A.E. Hoerl, R.W. Kennard, Technometrics. 12 (1970), 55-67.

25. A.E. Hoerl, R.W. Kennard, Commun. Statis.-Theor. Meth. A5 (1976), 77-88.

26. A.E. Hoerl, R.W. Kennard, Am J Math Manag Sci. 1 (1981), 5-83.

27. A.E. Hoerl, R.W. Kennard, K.F. Baldwin, Commun. Stat. 4 (1975), 105-123.

28. D.R. Jensen, D.E. Ramirez, Adv. Decis. Sci. 2013 (2013), 1-15.

29. A.I. Khuri, J.A. Cornell, Response Surfaces Design and Analyses, second ed., Marcel Dekker Inc., 1996.

30. A.I. Khuri, R.H. Myers, Technometrics, 21 (1979), 467-472.

31. T. Kunugi, T. Tamura, T. Naito, New Acetylene Process Uses Hydrogen Dilution. Chem. Eng. Prog. 57 (1961), 43-49.

32. K. Lin, J. Kmenta, Rev. Econ. Stat. 64 (1981), 488-494.

33. D.W. Marquardt, Technometrics.12 (1970), 591-611.

34. D.W. Marquardt, R.D. Snee, Am. Stat. 29 (1975), 3-20.

35. D.C. Montgomery, E. Peck, G.G. Vining, Introduction to Linear Regression Analysis, fifth ed., John Wiley and Sons, USA, 2012.

36. R.H. Myers, D.C. Montgomery, G.G. Vining, Generalized Linear Models With Applications in Engineering and the Sciences, John Wiley and Sons, USA, 2002.

37. R.H. Myers, D.C. Montgomery, Response Surface Methodology Process and Product Optimization Using Designed Experiments, second ed., John Wiley \& Sons Inc., UAS, 2002.

38. J. Neter, M.H. Kutner, C.J. Nachtsheim, W. Wasserman, Applied Linear Statistical Models, fourth ed., The McGraw-Hill Companies Inc., USA, 1996.

39. K.D. Pati, R. Adnan, B.A. Rasheed Ridge Least Trimmed Squares Estimators in the Presence of Multicollinearity and Outliers. Nat. Sci. 12 (2014), 1-8.

40. J.O. Rawlings, Applied Regression Analysis a Research Tool, Wadsworth \& Brooks, 1988.

41. T.A. Reddy, Applied Data Analysis and Modeling for Energy Engineers and Scientists, Springer, Boston, MA, USA, 2011.

42. S.M. Salh, Using Ridge Regression Model to Solving Multicollinearity Problem, Int. J. Sci. Eng. Res. 5 (2014), $992-998$.

43. R.A. Singh, A Survey of Ridge Regression for Improvement Over Ordinary Least Squares. IUP J. Comput. Math. III (2010), 54-74.

44. G. Smith, F. Campbel, Thisted et al, J. Am. Stat. Assoc. 75 (1980), 74-103.

45. R.D. Snee, J. Qual. Technol. 5 (1973), 67-79.

46. R.D. Snee, Technometrics. 19 (1977), 415-428.

47. T.D. Wallace, Econometrica. 40 (1972), 689-698.

48. W.B. Yahya, J.B. Olaifa, A Note on Ridge Regression Modeling Techniques. Electron. J. Appl. Stat. Anal. 7 (2014), $343-361$. 